\title{
"SUSTO", LOCURA Y POSESIÓN. ANTECEDENTES COLONIALES Y EXPRESIONES CONTEMPORÁNEAS EN LOS ANDES
}

\author{
“SUSTO”, MADNESS AND POSSESSION. COLONIAL PRECEDENTS AND \\ CONTEMPORARY EXPRESSIONS IN THE ANDES
}

\author{
Gerardo Fernández Juárez ${ }^{1}$
}

\begin{abstract}
La enfermedad del "susto" presente en toda América Latina, con especificidades culturales propias, ha sido analizada habitualmente bajo el perfil de los llamados "síndromes de filiación cultural", pero sin embargo poco se ha valorado bajo la perspectiva de los estados alterados de conciencia (EAC) que abren la puerta a su consideración dentro de los episodios de corte chamánico de los pueblos amerindios que fueron contemplados desde el prisma de la posesión demoníaca en el período colonial. El artículo ofrece un análisis comparativo de documentos coloniales y etnografías contemporáneas de la región andina.
\end{abstract}

Palabras claves: susto, locura, posesión, Andes, chamanismo, demonio.

The 'susto'(scare) illness, present across Latin America with local cultural characteristics, has been traditionally analyzed under the framework of the so-called 'culture-bound syndromes' and has been overlooked from the perspective of altered states of consciousness (ASC). This perspective opens the door to its consideration within Amerindian shamanic-like episodes that were conceptualized as demonic possession in the colonial period. This article presents a comparative analysis of colonial documents and contemporary ethnographies of the Andean region.

Key words: 'Susto', madness, possession, Andes, shamanism, demon.

\begin{abstract}
Antecedentes
Los estudios e investigaciones en Humanidades y Ciencias Sociales ameritan de propuestas interdisciplinares que suelen reflejar de manera más ajustada, correcta y razonable el trasunto de sus indagaciones. Es lo que propongo en el presente artículo donde modelos etnohistóricos basados en un ejemplo de las crónicas andinas del siglo XVII que define en términos edificantes un caso de posesión sobre una mujer española y otro "diferente" en relación con un indio, coincide con las versiones contemporáneas que en torno a la enfermedad del "susto" ha reflejado la etnografía andina contemporánea en diferentes contextos. Obviamente, las dimensiones que el articulo precisa a propuesta de la revista impide plantear aspectos teóricos o metodológicos de enjundia y
\end{abstract}

desarrollo en torno a la posesión, o los estados alterados de consciencia (EAC), si bien alguna referencia indicaré aprovechando las notas aclaratorias del artículo.

Una de las enfermedades prevalentes de carácter cultural con mayor expresión en toda América Latina es el "susto", objeto de diferentes estudios y monografías específicas en los últimos años (Neila Boyer 2006; Polia 1996; Rubel 1986; Rubel et al. $1995)^{1}$. Por lo que respecta a las poblaciones indígenas del Sur andino, su tipología ya sea en la consideración quechua (jap'iqa, mancharisqa) o aymara (katxiyata), implica inevitablemente el extravío de las entidades anímicas que integran la persona, por causa de algún suceso imprevisto que provoca su pérdida y la necesaria restitución según diferentes procedimientos terapéuticos de índole ceremonial. Este tipo de dolencia ha sido analizado desde la perspectiva taxonómica

\footnotetext{
1 Facultad de Humanidades de Toledo, Universidad de Castilla-La Mancha, Toledo, España. Gerardo.FJuarez@uclm.es
}

Recibido marzo 2018. Aceptado: diciembre 2018.

http://dx.doi.org/10.4067/S0717-73562019005001101. Publicado en línea: 29-mayo-2019. 
de los llamados "síndromes de filiación cultural" o "síndromes culturales"2, pero no así en función de sus posibilidades expresivas en el ámbito de la iniciación ceremonial de los especialistas rituales o los modelos andinos tanto de posesión, como de "locura", según la expresión de los propios informantes, asociadas a estados alterados de conciencia. Me propongo ofrecer en el presente artículo algunos ejemplos tanto coloniales como contemporáneos susceptibles de ampliar la consideración tradicional del susto, más allá de la simple "patología cultural" o no sólo como tal, para analizar otros ámbitos tan expresivos como pueden resultar los anteriormente indicados.

Ni que decir tiene que la significación demoníaca tanto en los procesos derivados de las iniciaciones ceremoniales como en las consideraciones sobre la locura y las lógicas interpretativas sobre la dolencia del "susto" que vamos a analizar constituyen resabios coloniales de los procesos de "diabolización" de las propias creencias, prácticas curativas y sistemas rituales indígenas andinos (Cervantes 1996; Fernández Juárez 2012).

Voy a presentar a cuestión un texto largo procedente de la crónica del agustino fr. (OSA) Alonso Ramos Gavilán en su relación de la Historia del Santuario de Nuestra Señora de Copacabana [1621] en el que se describen dos aparentes casos de endemoniados, según el criterio hispano de la época; el primero, una mujer española posesa en la localidad de Ancobamba cuyos rasgos coinciden en forma general con los tópicos del catolicismo sobre el modelo canónico de posesión ${ }^{3}$; a continuación describe el caso de un indio varón del que se decía endemoniado, pero con cualidades y características muy diferentes. El rasgo de la crónica y su utilidad metodológica para el presente artículo radica en el hecho de que existiendo una gran cantidad de relatos similares sobre modelos de posesión canónicos, cuyos ejemplos proceden de los relatos edificantes españoles de los Siglos de Oro y que impregnan incluso manuales al uso que justificaron en su día la "caza de brujas" en Europa, caso del célebre Malleus Maleficarum, encontramos aquí en un mismo texto, dos relatos alusivos a dos modelos diferenciados de describir el síndrome comparando el sucedido de una mujer española (lo usual en el caso de los relatos hispánicos edificantes de posesión), con el caso del indio en que el relato presenta otros componentes de interés casi etnográfico. No me queda más remedio que utilizar las notas aclaratorias a pie de página como registro metodológico explicativo del relato para, de esta forma, evitar el corte sistemático de su ritmo informativo:

El año de mil y seiscientos y diez y siete, por el mes de Abril, en la provincia de los Aymaraes que (como ya he dicho otra vez) pertenece al Obispado del Cuzco. En un pueblo llamado
Ancobamba, por secretos juyzios de Dios nuestro Señor, se apoderó el demonio de una mujer Española, y casada; cuyo nombre callo por no importar a la historia. Los primeros días usó de sus ardides y mañas el demonio para no ser conocido, ya enmudecía unas vezes, y ya otras hablava con tan grande modestia, que ni aun pequeños barruntos dava de sí, y quando vencido de su mala inclinación atormentava a la muger; luego cessava por no ser sentido, y dissimulávase más, con públicas accciones de Religión; porque rezava y assistía a los divinos Oficios, sin turbar el semblante; pero por demás el lobo se viste con piel de oveja, si su mala inclinación a de descubrir, que es lobo, por más que usava de sus hipocresías. Porque la enemistad que con los hombres tiene, a pocos lances descubrió su fiereza. El rostro de la muger, que solía ser antes apacible y hermoso, se trocó en abominable y fiero, los ojos alegres, en encarnizados, los labios rojos, se pusieron morados, y demasiadamente gruessos, los cabellos tenía perpetuamente erizados, al fin todo el cuerpo, y su figura mostrava la malicia del oficial que assí la dispuso, y el desaliño de la casa descubría bien, que era poco asseado el huésped. Bien se descubría por el humo el fuego, mas la ninguna experiencia, que de semejantes casos tenían los Sacerdotes de aquella Provincia, fue causa a los principios de no hazerse tan de veras los exorcismos, para expeler al demonio, atribuyendo aquella mudança a frenesí y a otros acidentes, mas el enemigo que se aprovechava a su contento de aquellas dudas, maltratando aquel cuerpo, se dio más priessa en darse a conocer, que los Sacerdotes en conocerle. [...] Conocieron, pues, los Sacerdotes, que el demonio estava apoderado del cuerpo de aquella muger, y dieron principio a expelerle con los exorcismos, y cerimonias que tiene establecidas la Iglesia, mas estuvo rebelde por muchos días, entreteniendo a todos con embustes, y mentiras, que por tales tengo las faltas que publicó de muchas personas, argumento grave para temer pues mal callara las culpas del delincuente quien fabrica delitos y haze dueños dellos a quien no los cometió. Viéndose una vez apretado el demonio con los exorcismos, respondió a vozes, que era la voluntad de Dios estuviesse en aquel cuerpo, y que no presumiesen echarle del Clérigos, ni Religiosos de tales y tales Ordenes, repitió esto por muchas vezes, y una entre otras advirtió uno de los presentes, que entre las Religiones que 
excluya el demonio, nunca nombró la de nuestro Santo Padre San Agustín, de donde se dieron a pensar, que algún Religioso de esta Orden avía de expelerle; y por esta razón despacharon un mensagero, que fue el mismo marido de la opresa, que me fue a llamar por más vezino, que en esta coyuntura me tenía ocupado la obediencia en dotrinar a los Indios de Chirirque, y Chuquibamba, dotrinas y pueblos que tiene a su cuydado nuestra Religión, en la Provincia de los Omasuyos, entristecióse el demonio de manera, que los circunstantes echaron de ver y coligieron era cierta su expulsión. [...] llegué a la Iglesia del pueblo donde hallé gran número de gente que por no aver visto en aquellas partes otro semejante suceso, venían de varios lugares, assi Españoles, como Indios traydos de la novedad, luego que el Demonio me vio se turbó, y no apartava los ojos de $\mathrm{mi}^{4}[$... $]$ Llegado el sexto día que fue un Domingo, día en que forzosamente se avían de juntar los Indios a la missa mayor, y avían de acudir de dos curatos, por que dos sacerdotes clérigos a cuyo cargo estavan aquellos beneficios, se detuvieron en el Pueblo para ayudar, y favorecer a la pobre opresa, Aqueste día al tiempo de dezir la misa mayor, estando toda la Iglesia llena de gente, proseguí con los exorcismos valiéndome de los meritos de San Juan, cuya Imagen puse en el altar, echóse de ver que el Demonio se rendía con la virtud dellos, porque començó a estremecerse, y a sudar, manifestando que el gloriosso santo le atormentava, y que San Agustín y San Nicolás hechos a una contra él le oprimían, hallando tan buena ocasión, y que avía gran número de gente, compelí al enemigo acudiesse a lo que ya le tenía mandado que era el desengaño de aquella miserable gente, començó pues el demonio su habla, era áspera su voz, y muy penetrante, declaró que era Demonio, y Angel de la suprema hierarchía a cuyo cuydado estava el govierno de los Demonios inferiores que andavan por orden suya repartidos, por todas las Provincias de los Aymaraes, dixo que su nombre era Satáfico, compuesto del verbo latino (Sero seris, y del nombre Ficus), que junto significa lo mismo que sembrador de cosas malas, y manifestó a los Indios la vanidad de sus ydolatrías, y persuadióles, la unidad de Dios, la Trinidad de las personas, la Encarnación del verbo, díxoles finalmente que eran caudalosísimas las cosechas de almas, que el Infierno cogía en sus trojes y que temiesen a Dios, adorándole a él sólo como a Señor, y Criador, y que se dexasen de Idolatrías, y que la causa de estar vexados, era por apartarse de Dios, y darse a la adoración de sus falsos Dioses, muchas verdades dixo el demonio, a su despecho ese día y importó mucho que él las dixesse, para que los Indios se desengañasen, de la afición que tienen a la ydolatría [...] Antes de la expulsión de aqueste cruel enemigo, començó dentro de la Iglesia, a llover un menudo rocío, sobre todos los que estávamos presentes a la expulsión, siendo assí, que el cielo estava sereno, y limpio de nubes, no advertí de preguntarle la significación de aquella maravillosa lluvia, porque de todo punto me ocupé, en compelerle saliesse de aquel miserable, y lastimado cuerpo, como lo hizo, dando por señal de su salida, un ramo de oliva silvestre, que los Indios llaman Quisuar, que echó por la boca de la muger, aviéndosele pedido, echase qualquier cosa, de las que en sacrificio le ofrecían, vivió tres días, y en ellos se dispuso, para morir buenamente, y no bolver a las manos de tan cruel enemigo, yo fío en la misericordia de Dios, que no se perdió su alma (Ramos Gavilán 1988 [1621]:99-107).

El relato de la española endemoniada presenta rasgos similares a los encontrados a modo de exempla o prueba de verificación en los tratados de magia y brujería de la época para mayor gloria divina (Zamora Calvo 2005). No conocemos las razones de la posesión de la mujer, ese "pecado" inicial que genera la crisis y que suele curarse con el reacomodo de la conducta social femenina inadecuada al consenso social y católico de la época; pero su caso acredita, en esta ocasión, el derecho de la Orden Agustina sobre el territorio de gracia del Santuario de la Virgen de Copacabana así como el prestigio de sus milagros, puesto que sólo ellos, los agustinos, son reclamados implícitamente por el propio diablo para ejecutar el exorcismo de forma eficaz. El poder del exorcista es tal que incluso el demonio, habitual mentiroso en los proceso de exorcismo, exhorta a los indios en la eucaristía del domingo en una iglesia repleta ${ }^{5}$, a abandonar sus idolatrías, a la vez que insiste y predica tenazmente la veracidad de la Trinidad y otros dogmas católicos actuando a la manera de elocuente pastor eclesiástico. El relato resalta la muerte de la mujer a los pocos días de finiquitada la expulsión del demonio, una vez sacada de las garras del maligno, con la confianza de la salvación de su alma por parte del relator.

Por lo que respecta a la posesión en sí, encaja la descripción en los modelos clásicos del catolicismo peninsular: las transformaciones corporales de la endemoniada, el efecto de las oraciones y las santas reliquias sobre su cuerpo; las imágenes sagradas; las reacciones violentas; los espumarajos por la boca, las 
crisis corporales; el modelo de expulsión corporal y su cristalización en el ramo de kiswara, pequeña oliva silvestre que todavía puede apreciarse en ciertos sectores del Altiplano aymara ${ }^{6}$. Comprobamos en territorio americano, la perfecta adaptación de los maleficios corporales a las especies naturales del lugar, según los relatos de los cronistas?

El autor incide en dos ocasiones en el valor excepcional de la posesión y el subsiguiente exorcismo en aquellas alturas altiplánicas. Tanto es así que los sacerdotes al principio lo consideran tan solo un "accidente" de la mujer sin ninguna implicación diabólica. Es decir, el relato parece insistir en que la posesión demoníaca tal y como era conocida en Europa a través de los tratados de magia y brujería y formulada expresamente en los casos de espiritadas y energúmenos que son los que, habitualmente, materializan la salida del maligno en los diferentes materiales que encarnan los maleficios corporales, carece de parangón en el caso de los indígenas y sus cuerpos en aquel contexto colonial.

Pero entonces ¿qué decir del caso del indio endemoniado que el propio autor describe posteriormente en la misma crónica? Veamos sus caracteres:

Mudo, y endemoniado (dize San lucas) estava aquel hombre a quien Christo sanó. Mudo, tullido, y poseído del demonio estava un pobre Indio que después que sanó vivió mucho tiempo en Copacabana por medio de la soberana Virgen María. Mas qué querrá ésta tan alta Señora que no lo quiera el Señor, pues su voluntad fue siempre cortada al talle y medida de la voluntad divina, que todo lo puede; que como dice San Bernardo, ¿qué pedirá el pecador a la Virgen que no se lo conceda? y ¿qué pedirá la Virgen al Hijo, que no se lo otorgue? y ¿qué pedirá el Hijo al Padre, que no venga en ello? de suerte, que quien tuviere a la Virgen, y le pidiere algo lo alcançará Della, y de toda la Trinidad. Y quién (como dize San Inocencio) se llegó a esta Virgen, que no hallasse en ella singular socorro y admirable consuelo, pues es por quien Dios se acuerda de sus mayores enemigos, y les haze bien, y en este sentido se explica aquel verso de David. Memor oro Rahab, et Babylonis Scientium me. La historia del Indio Energúmeno passa assí, tienen los Naturales de toda la comarca recurso a los Yungas de Larecaja, de donde con su trato y rescate traen de retorno, coca, agí, fruta, algodón, y otras cosas, de que carecen acá en la sierra, un año acaeció que entre los demás traginantes, fue uno llamado Domingo Calisaya, mancebo de edad de 23 años, el qual ora porque el temple de la tierra le quadró, ora porque alguna otra ocasión a ello le obligasse, se detuvo en los Yungas el tiempo que bastó para que un viejo gran hechizero y cultor de guacas, compatriota suyo encontrasse con él, y teniéndolo a buena dicha determinó prohijarle, y nombrarle por sucessor en su oficio diabólico y perversa prevenda. Diole a entender era aquella la determinación, y voluntad de los Idolos, que assi se lo tenía revelado, y que se tuviesse por dichoso, pues sus Dioses avían puesto en él los ojos, para le proveer en cargo tan aventajado como aquél, no concedido a todos, sino a los escogidos, y de mayor confianza, el moço que por ventura hasta entonces, no devía de aver tratado aquel lenguage, encogiéndose se escusó diziendo que él no se hallava para aquel oficio, ni lo avía jamás aprendido, ni ejercitado, porque en la doctrina assí clérigos como frayles, no le avía enseñado aquello, antes les avían dicho, y oydo predicar, que las guacas eran demonios, y que se condenavan todos los que las adoravan, no le valieron estas escusas al pobre mancebo, porque el maldito viejo con una eloquencia de Satanás, pudo tanto con el triste Indio que le vino a rendir, acabando con el que prestasse consentimiento a lo que le dezia, pues era aquella la voluntad de los Idolos. Luego lo instruyó en sus cerimonias, y ritos, ordenándole ministro de los Idolos, y señalándole los lugares de la adoración, le dixo que él se yva a morir, y muy gozosso, porque le dexava por su lugar teniente, de cuya solicitud, y fidelidad yva enterado, y lleno de grandes confianças, que advirtiesse mucho en las obligaciones que corrían por él de allí adelante. Tan mala maña se dio el pobre y mal aconsejado moço, que pudo Satanás a quien él se avía ya dedicado, tomar posesión en los sentidos de su cuerpo, y apossentarse en ellos, y la paga del hospedaje fue tullirle, y enmudecerle, para que ni con los pies pudiesse acudir al remedio, ni con la boca manifestar los daños de su alma, dificultando con esto más su reparo, y medicamento. Las armas que contra el demonio tiene el Christiano es la lengua, pues con ella descubre al confesor sus culpas, y pecados, y para que este pobre Indio, que se le avía ofrecido, y entregado, no pudiesse salir de su poder quítale las armas, es a saber, prívale de los pies dexándolo tullido, para que no pueda acudir al remedio, y para que no manifieste su mal, ni pueda salir del, prívale de la lengua dexándole mudo, que este es el galardón y premio del demonio que assí paga a los que le siguen, y se entregan a su servicio [...]quitó al miserable Indeçuelo la habla, para que no pidiesse cególe la puerta, echóle el cerrojo; pero 
en nuestro caso se verá que le valió muy poco, no faltó quien diesse la triste nueva a la pobre de su madre, que no sabía del, la qual aunque no dio alcances a la enfermedad del alma, dio orden cómo traelle a su pueblo y casa, donde padeció con él muchos trabajos, porque no parava ropa en su cuerpo, y para que comiesse era menester con estar tullido, que le atassen pies, y manos, tan enemigo estava de sí mismo, que muchas vezes acometió a despeñarse [...] Teniendo noticia del trabajo, y miseria, en que estava este pobre Indio, el padre Montoro movido a compasión le fue a ver, y luego sintió en el aspeto, y movimiento de dónde le venía el daño que era del mal huésped, que le avía puesto tan abominable, que asombrava a todos quantos le miravan [...] acordó (el padre) ayudarle con algunas Missas, dichas en el altar de la Virgen, y para esto mandó que en una manta se lo llevasen a la Iglesia, y le pusiesen en el altar de la Virgen ( claro, de Copacabana), assistió el enfermo a la primera Missa, aunque algo sosegado, más de lo que se pensó, fue necessario le tuviesse la madre assido a quien él guardava algún respeto, perdiéndole de ordinario a todos; otro día a la segunda Missa assistió de la misma manera aunque con señales de mejoría, porque sufrió tener una candela en la mano, lo qual dio grandes esperanças de salud, y assí fue, y tan ciertas salieron, que sacando al enfermo los que le llevavan hasta la puerta de la Iglesia, asentándole allí para assirle mejor, se levantó en pie, [...] Habló como atónito y espantado, y de ay adelante pudo andar y dar razón de lo que le avía passado en los Yungas con el hechizero... (Ramos Gavilán 1988 [1621]:251-255).

Frente a la versión de la endemoniada española que cumple con el estereotipo propio de la mujer posesa, en términos europeos, hasta el final con la expulsión del maligno bajo la forma del ramo de kiswara, la del indio de los Yungas de Larecaja ${ }^{8}$ presenta otras características y matices distintos bien definidos en el relato.

La llamada "posesión" del indio "endemoniado" adquiere diferentes tipos de limitaciones que le incapacitan para la vida social cotidiana: mudo y tullido de repente, marcado carácter antisocial, falta de policía personal y de control. Tras sufrir esta serie de crisis episódicas, el indio "endemoniado" se cura de forma rápida e igualmente sorprendente (tras la escucha de las dos misas). Esta forma de entender el padre Alonso de Gavilán la posesión del indio coincide en realidad con el proceso de iniciación que está sufriendo en su aprendizaje al servicio de las huacas. La pérdida del habla y el tullimiento junto con el "susto" que sufre, forman parte de los valores sensibles del proceso de iniciación de los actuales especialistas rituales aymaras y quechuas ${ }^{9}$. El hecho de la limitación funcional repentina y su igualmente repentina curación constituye una de las características presentes en los relatos de iniciación ceremonial en los Andes que recoge la actual etnografía. No se trata por tanto de una "posesión" al uso europeo, sino de un trance, un estado alterado de conciencia $(\text { EAC })^{10}$ propio de la condición de los noveles "maestros ceremoniales", como corresponde a su condición de "servidor de las huacas"11. Es decir, el demonio en principio parece tomar posesión "canónica" de los cuerpos de los españoles y mestizos, particularmente en el caso de mujeres ${ }^{12}$, pero no así de los cuerpos de los indígenas originarios, al menos durante los siglos XVI y XVII del período Colonial ${ }^{13}$. Son los clérigos y sacerdotes quienes relacionan los procesos de iniciación ceremonial indígenas con la posesión satánica.

Encontramos otros referentes similares de iniciación ceremonial en diferentes contextos andinos coloniales recogidos por los cronistas que achacan protagonismo al demonio en su lógica pugna por la extirpación de las idolatrías de los indios, así lo vemos en la conocida Crónica Agustina de Huamachuco [1560] atribuida a fr. Juan de San Pedro (2007 [1560] o en algunos casos de extirpación de idolatrías de la Sierra de Lima como en el que recoge Ana Sánchez en Chancay, en el año 1662, sobre el indio Francisco Felipe natural de la doctrina de Auquimarca del que se decía había sido arrebatada su alma ${ }^{14}$ por una huaca:

...que había su cuerpo quedado a orilla de un río y su alma había entrado en una huaca donde estaba una mesa muy grande de oro y plata y platos de lo mismo. Y muchos hombres sentados comiendo, y que así se había visto aquello había temblado de pies y manos. Y que los que estaban sentados a la mesa lo mandaron entrar a la sala, porque estaba en la puerta, y que dijeron: este se ha de quedar aquí. Y que le salvó un fraile franciscano, y en esto del fraile franciscano varió porque después dijo que un negro. Y que el fraile le dio con el cordón y le dijo: ¡anda vete! vete a tu casa hijo. Y que el rey que estaba sentado a la mesa le dijo ¡no! déjenlo aquí. Y que el fraile volvió y dijo: Señor, déjelo usted que este es un pobrecillo y no sabe nada (f.IV) (Sánchez 1991:V).

Este sueño que incorpora la escena del banquete ceremonial, combinado con la pérdida de conciencia y el estado de aflicción previo compatible con el padecimiento de "susto", resulta muy similar al que 
pude recoger a principios de los años noventa del pasado siglo como sueño de iniciación de un ch'amakani aymara en las comunidades ribereñas del Lago Titicaca e incluso Douglas Sharon (1980) describe una escena parecida en la iniciación ceremonial de un chamán zinacanteco. Obviamente cualquier comparación de datos separados por tanto tiempo es tan sólo una intuición epistemológica, pero que sí nos permite pensar y razonar en algunas de las formas que adquieren estos síndromes de filiación cultural en los relatos etnográficos andinos contemporáneos, al menos, en una breve antología de ellos.

Los estudios antropológicos en los Andes Centrales acreditan, a través de las monografías existentes sobre grupos étnicos americanos en la actualidad, la presencia de formas de éxtasis y estados alterados de conciencia (EAC) en contextos amerindios asociados al consumo de sustancias alucinógenas, caso del sanpedro o achuma (Trichocereus pachanoi), en la costa Norte del Perú; el "floripondio" o wantuq (Datura arborea) del género de las Brungmansiae al igual que las "mishas"; la ayahuasca (Banisteriopsis caapi) en contextos amazónicos, o la propia achuma y la willca (Piptademia macrocarpa) presente en los Andes del Sur durante el período colonial.

La posesión diabólica en términos canónicos que padecen las mujeres españolas, pero que no parece incidir en los indígenas, en la primera centuria del proceso colonial, justifica el empeño por otorgar a la recuperación corporal de los indios (higiene, adecentamiento y policía del cuerpo y hogares), lo que va a suponer la cristianización católica del alma ${ }^{15}$, como empeño necesario para que los propios indios, con el tiempo sean vulnerables a las acechanzas del diablo. Parece que sólo el alma sometida al proceso de cristianización es voluble a las insidias diabólicas. No hay posesión "diabólica" si no hay "alma" cristiana que la revele y soporte ${ }^{16}$.

Precisamente la concepción de ser humano entre los grupos amerindios parece una cuestión crucial en lo que estamos analizando. En numerosos ejemplos recogidos por las etnografías de los pueblos de América, los grupos amerindios se identifican a sí mismos como "seres humanos" por el justo acomodo entre su realidad corporal y un conjunto de entidades anímicas que presentan diversas texturas, características y ubicación corporal. Estas entidades anímicas son las que pueden extraviarse produciendo esa dolencia genérica en gran parte de Iberoamérica que denominamos "susto".

\section{“Susto” y Posesión: Versiones Andinas}

La vinculación que realizan los sacerdotes y clérigos del ámbito colonial entre la posesión demoníaca y la iniciación chamánica a partir de la sintomatología del "susto", está presente en los discursos etnográficos contemporáneos de algunas poblaciones indígenas andinas.

Los pastores quechuas de las alturas del Ausangate han desarrollado discursos efectivos en los que la dolencia del "susto" no puede solventarse sin acudir a formulas peculiares de exorcismo:

Todo aquello que puede ser el fruto de un hechizo lanzado por alguien, sal del cuerpo de este hombre. Suéltalo, tú estás destinado al apu Hururu. Me dirijo a ti, ya sea el wayra, o el suq'a, o el qhaqya, o el machu, si eres tú el machu qhaqya quien se le ha prendido, sal ahora del cuerpo de este hombre, todo esto, tú que este hombre ha incubado en su seno, para su propia muerte, el fruto de un hechizo destinado a causar su pérdida, a enfermarlo, sal pues, sal del cuerpo de este hombre (Ricard 2007:186).

El ofrecimiento de "despachos", ofrendas rituales complejas elaboradas con la sucesión de ingredientes gustosos para la entidad que causa el "susto" desde los adentros corporales del doliente, se pasa por el cuerpo del enfermo para que se impregne de sus esencias corporales y limpie la dolencia al tiempo que pretende "convencer" a la entidad maléfica a que salga de su interior:

Braulio pasa sobre su cuerpo el despacho, envuelto en una manta de lana de alpaca (unkhuña, wachala), como para acercar la ofrenda al agente patógeno a quien está destinada. El despacho contiene fetos de cuy, de gallina y de chancho [...], las doce hebras de colores retorcidas hacia la izquierda (kuti), las tres variedades de sulfatos (qullpa), un maíz de tipo sara kuti, y también cruces (sin duda un préstamo a los rituales de exorcismos católicos) en madera de chonta, Leonardo no para de decir: 'Tú, su dolor de cabeza, sal, su dolor de pies, sal, su dolor, como si el cuerpo estuviese en pedazos, sal, su dolor de pies, sal, su dolor de cuerpo, que lo ata, sal, salgan todas las enfermedades, ya sean ustedes wayra o cualquier otra enfermedad mala, ustedes que están en el interior del cuerpo de este hombre, salgan. Ahora, has recibido tu ofrenda, has sido servido, ya, has sido destinado, has sido separado' (Ricard 2007:186).

Se incita a la entidad maléfica que está dañando el cuerpo de Braulio Ccarita a que salga sobre la ofrenda que se roza sobre el cuerpo del enfermo y a la que gusta la entidad maléfica. La ofrenda culinaria ritual no es suficiente en este caso, por eso se recurre a la violencia 
del látigo (chicote) que si bien en las alturas potosinas se empleaba como recurso para obligar a la entidad anímica extraviada, ch'iwi, "sombra" a regresar y "volver" sobre el cuerpo del enfermo, en este caso es todo lo contrario, se trata de una estrategia coercitiva para que la entidad andina gestora de la enfermedad desde el interior del cuerpo de la víctima, salga y propicie su curación:

[A Braulio] Dile tú: “Ahí está tu pago, ahí está tu merienda. ¡sal de mi cuerpo!” “Suéltame!” ¡dile!'Luego, Braulio pasa sobre todo su cuerpo un cuy vivo. El cuy es también muy apreciado por el $m a c h u^{17}$. Se espera que este último pase al cuerpo del animal ${ }^{18}$. La última secuencia del ritual es la del exorcismo propiamente dicho: recordando las ofrendas que han sido realizadas, Leonardo invoca con fuerza al animu del agente patógeno, y lo conmina a abandonar el cuerpo del enfermo. Las invocaciones son cada vez más virulentas. Los apu auxiliares del chamán son mencionados también constantemente. Finalmente, se recurre al látigo; las tiras del flagelo silban en la habitación y caen sobre los hombros de Braulio. La sacudida debe también incomodar al machu; eso es lo que se espera. Los azotes, conjugados con las ofrendas, deben decidir la expulsión del machu fuera del cuerpo. Esta fase final es particularmente violenta: los participantes, sumergidos en la más total oscuridad, reciben también azotes. No hay que abrir los ojos, para no ver al machu abandonando a su víctima: "Sal, este hombre es tragón de sal y ají, sabe hacer sus rezos, es un hombre bautizado $^{19}$. Sal maligno, sal, ispiritu malo, sal lo que ha sido hecho por el hombre, la brujería del hombre, el chancho, la gallina; ;sal! [...]. Sal, esto es para ti, es tu ofrenda, tu merienda para el camino, sal, véte, sal para siempre, ya está, tú eres qullpa. "Cabeza que da vueltas", desfallecimiento, ustedes han prosperado, han crecido en vigor, en el cuerpo de este hombre, sal maligno, sal, brujería hecha por un hombre". [Silencio. Sonido de campanitas] "Kuti, kuti, kuti, contra hechizo, contra veneno, contra siete venenos, haz que se vaya-kutiy- lo que ha hecho ese hombre malo, para que [Braulio] esté agarrado, cogido ${ }^{20}$. Dolor de cabeza, dolor de espalda, dolor de estómago. Quien sea que lo haya cogido, el wayra, el qhaqya, el suq'a, el machu. Todos, salgan ahora, nudos de las manos, nudos de los pies, lo que el hombre ha hecho con el fin de atar. Kuti, kuti, kuti : que esto se invierta, que estas enfermedades salgan ahora de tu cuerpo ${ }^{21}[\ldots]$ ". [Sonido de campanitas]. "Sal ahora, es tu ofrenda, es tu derecho, es tu derecho. Sal, wayra, sal uraña, sal, machu, sal suq'a, nudos de los pies, nudos en todo el cuerpo, quien seas, uraña, qhaqya, machu, suq'a, sal Satán, diablo. Este hombre come sal, y ají, sabe rezar, es bautizado, este hombre que está aquí... (Ricard 2007:186-187).

La complejidad del exorcismo establece en ocasiones la posibilidad de que la entidad maléfica sea "escupida" y que escape por el ombligo del enfermo violentado por los seres tutelares andinos que velan principalmente por la protección de los pastores del Ausangate: "Entonces, atrapan a este machula, también, y lo hacen hablar, a latigazos, obligan al machula a escupir el animu del enfermo, que sale por el orificio de su ombligo" [José Sarmiento] (Ricard 2007:188).

La posesión en términos andinos posibilita ese juego de depredación sistemática entre mutuos comedores. Tras la expulsión de la entidad maléfica que aprovechó y generó el susto para introducirse en el cuerpo del enfermo, la dolencia se cura, junto con toda la parafernalia ceremonial de las ofrendas rituales.

Es así que en contextos amerindios las enfermedades pueden ejemplificarse como formas de posesión espiritual $^{22}$ en el caso de los acontecimientos de tipo "susto" protagonizado por entidades maléficas identificadas, por efecto de la prédica colonial, con el diablo, o bien otras que penetran los adentros corporales materializando su entidad maligna en los diferentes objetos que se sustraen de su interior.

Estos recursos terapéuticos son empleados por la contundencia que tienen las aflicciones descritas en comprometer el concepto de persona, de "ser humano", que es el trasfondo que la aflicción del "susto" pone en serio riesgo. Las modalidades de extracción de objetos que materializan la enfermedad, como podemos ver en diferentes contextos amerindios, también en clave colonial y la recuperación de las entidades anímicas extraviadas que hay que incorporar de nuevo en el enfermo contribuyen a restaurar el acuerdo entre las entidades anímicas del enfermo y su realidad corporal de cuyo acomodo depende la salud de los seres humanos. Planteamiento muy diferente al relato colonial de la española posesa cuya expectativa de cura esta versada en un conflicto moral que afecta muy especialmente a las mujeres en los dominios colonial americano, pero también en el peninsular y europeo de la época (Guazzo 2002 [1608]; Farberman 2005; Sprenger y Kraemer 2004 [1486]).

La pervivencia en el tiempo de este tipo de configuración de dolencias y aflicciones entre los indígenas de los Andes abre múltiples posibilidades de análisis a los modelos interpretativos de la psiquiatría transcultural para valorar de una forma más adecuada conceptos que aparecen contaminados por la proyección conceptual colonial sobre dichas patologías amerindias. 


\section{Referencias Citadas}

Bernabé, C. 2002. La curación del Endemoniado de Gerasa desde la antropología cultural. En Los Milagros de Jesús. Perspectivas Metodológicas Plurales, editado por R. Aguirre, pp. 93-120. Verbo Divino, Estella.

Bernand, C. y S. Gruzinski 1992. De la Idolatría. Una Arqueología de las Ciencias Religiosas. FCE, México D.F.

Bernand, C. 2010. Los nuevos cuerpos mestizos de la América colonial. En Retóricas del Cuerpo Amerindio, editado por M. Gutiérrez y P. Pitarch, pp. 87-116. Iberoamericana, Madrid.

Bieñko de Peralta, D. 2008. El cuerpo de la posesa. discurso y práctica en torno a la posesión demoníaca en la Nueva España. Destiempos.com 14:142-149.

Cervantes, F. 1996. El Diablo en el Nuevo Mundo. El Impacto del Diabolismo a Través de la Colonizacion de Hispanoamérica. Herder, Barcelona.

CRÓNICA AGUSTINA DE HUAMACHUCO (Atribuida a Fray Juan de San Pedro) 2007 [1560]. En La Persecución del Demonio. Crónica de los Primeros Agustinos en el Norte del Perú (1560) Fray Juan de San Pedro. Manuscrito del Archivo de Indias, editado por E. Deeds, pp.146-229. Algazara, Málaga.

Farberman, J. 2005. Las Salamancas de Lorenza. Magia, Hechicería y Curanderismo en el Tucumán Colonial. Siglo XXI, Buenos Aires.

Fernández Juárez, G. 2012. Hechiceros y Ministros del Diablo. Rituales, Prácticas Médicas y Patrimonio Inmaterial en los Andes (Siglos XVI-XXI). Abya-Yala, Quito.

Fernández Juárez, G. 2017. Brujería y Aquelarres en el Mundo Hispánico. Una Antropología de Contrastes. Abya-Yala, Quito.

Girault, L. 1987. Kallawaya. Curanderos Itinerantes de los Andes. OPS/OMS/UNICEF, La Paz.

Guazzo, F.M. 2002 [1608]. Compendium Maleficarum. Club Universitario, Alicante.

Gutiérrez, M. 2010. Esos cuerpos, esas almas. Una introducción. En Retóricas del Cuerpo Amerindio, editado por M. Gutiérrez y P. Pitarch, pp. 9-55. Iberoamericana, Madrid.
Miquel Pericás, E. 2009. Jesús y los Espíritus. Aproximación Antropológica a la Práctica Exorcista de Jesús. Ediciones Sígueme, Salamanca.

Moncó, B. 2005. Demonios y mujeres. Historia de una transgresión. En El Diablo en la Edad Moderna, editado por M. Tausiet y J. Amelang, pp.187-210. Marcial Pons, Madrid.

Neila Boyer, I. 2006. El "samay", el Susto y el Concepto de Persona en Ayacucho (Perú)". En Salud e Interculturalidad en América Latina. Antropología de la Salud y Crítica Intercultural, editado por G. Fernández Juárez, pp.187-215. Abya-Yala, Quito.

Noydens, B.R. 1675. Practica de Exorcistas y Ministros de la Iglesia. En qve con Mucha Ervdición y Singular Claridad se Trata de la Inftruccion de los Exorcifmos... Imprenta de Antonio Lacavallería, Barcelona.

Polia, M. 1996. "Despierta, Remedio, Cuenta...”: Adivinos y Médicos del Ande (dos tomos). Pontificia Universidad Católica del Perú, Lima.

Ramos Gavilán, A. fr. 1988 [1621]. Historia del Santuario de Nuestra Señora de Copacabana. Ignacio Prado Pastor, Lima.

Ricard, X. 2007. Ladrones de Sombra. El Universo Religioso de los Pastores del Ausangate. IFEA y CBC, Cusco.

Rubel, A. 1986 [1966]. El susto en Hispanoamérica. Arinsana 1:29-42

Rubel, A., C. O’Nell y R. Collado 1995 [1984]. Susto. Una Enfermedad Popular. FCE México D.F.

Sánchez, A. 1991. Amancebados, Hechiceros y Rebeldes, Chancay, Siglo XVII. Centro de Estudios Regionales Andinos "Bartolomé de las Casas", Cusco.

Sharon, D. 1980. El Chamán de los Cuatro Vientos. Siglo XXI, México D.F.

Sprenger, J. y E. Kraemer 2004 [1486]. El Martillo de las Brujas. Para Golpear a las Brujas y sus Herejías con Poderosa Maza. Malleus Maleficarum. Maxtor, Valladolid.

Tausiet, M. 2002. Los Procesos de Tosos (1812-1814). Brujería y Justicia Popular en Tiempos de Revolución. Instituto Aragonés de Antropología, Zaragoza.

Zamora, M. J. 2005. Ensueños de Razón. El Cuento Inserto en Tratados de Magia (Siglos XVI y XVII). Iberoamericana, Madrid.
${ }^{1}$ Hoy el "susto" posee una presencia notable y extensa en el dominio indígena y mestizo tanto en Mesoamérica como en América del Sur, constituyendo una de las dolencias prevalentes en toda América Latina. Con respecto a su origen algunos expertos inciden en su probable vinculación hispánica y europea a través del concepto de "pasmo" (Bernand 2010).

${ }^{2}$ Los llamados "síndromes de filiación cultural" son enfermedades expresadas y sentidas bajo el dominio de un marco propicio de expresión cultural que les da sentido. Tienen presencia en toda América Latina, con especial incidencia en los grupos amerindios son tremendamente versátiles, tanto en su sintomatología, como en el diagnóstico y procedimientos terapéuticos que precisan. Dado los límites marcados por la normativa de la revista para los artículos es imposible desarrollar aquí sus diferentes taxonomías (kharsutas, "empacho", "caída de mollera", "mal de ojo", "agarrado por la tierra", "enfermedad de la vergüenza", "enfermedad de los antiguos"... etc.). Me centraré en exclusiva en la casuística del "susto" por su gran extensión en América Latina y su presencia en la actualidad en el contexto andino sobre el que versa el presente artículo.

${ }^{3}$ Sobre los criterios de reconocimiento de posesas y endemoniados, oraciones y prácticas ceremoniales vinculada al exorcismo católico en el contexto del siglo XVII, ver Noydens 1675.

${ }^{4}$ En este momento el relator describe varias fases del exorcismo, con la imposición de reliquias, oraciones, eucaristía y ofrecimiento de la sagrada hostia, con los consiguientes retorcimientos corporales de la endemoniada (Ramos Gavilán 1988 [1621]). 
${ }^{5}$ Recordemos el valor teatral y espectacular de los exorcismos que eran contemplados por los lugareños, en la celebración eucarística con la máxima curiosidad como podemos recordar en el caso de las Ursulinas de Loudun [1632] o el de las brujas de Salem [1692] en Nueva Inglaterra.

6 "Buddleja longifolia H.B.K: especie espontánea de los valles altos (3700 m)" (Girault 1987). Presenta diferentes variedades específicas.

${ }^{7}$ En el Noroeste argentino del siglo XVIII entre las provincias de Santiago del Estero y San Miguel de Tucumán, encontramos esta referencia sobre un maleficio expulsado por una tal "Ana Jiménez, quien "enferma de maleficio, entre otras sabandijas que arrojó por la boca, echó una taleguita de una cinta negra atada con hilo colorado en la cual hallaron un quirquincho" (Farberman 2005). El quiquincho es el nombre coloquial por el que se conoce al armadillo andino en el noroeste argentino y también en ciertas zonas de Bolivia. Igualmente los "alfileres" a que se refieren en los maleficios son en realidad púas de quimil, una cactácea frecuente en las laderas montañosas de Santiago del Estero.

8 Valles cálidos próximos a La Paz en Bolivia; entrada natural desde el Altiplano a los bosques tropicales amazónicos. Se caracterizan por la producción de diversos frutales, destacando los cítricos, variedades de maíz y coca.

9 De hecho, según recoge Beatriz Moncó (2005) en su investigación sobre las monjas del convento madrileño de San Plácido en 1628 , la posesión de mujeres en aquella época otorga un papel preponderante a la palabra caracterizada por las expresiones de las monjas poseídas y los demonios. Aquí vemos una clara diferencia con respecto al indio "endemoniado" que enmudece como expresión de su proceso ritual. De hecho uno de los atributos específicos de los "servidores" de las huacas del dominio colonial andino era, después de su iniciación correspondiente, hablar con ellas o ser sus mediadores con respecto a los pobladores locales en los pronósticos, consultas y augurios efectuados por ellas.

10 "La Antropología encuadra el fenómeno de las posesiones en lo que se denomina "estados alterados de conciencia". Son estados que sufren algunas personas en los que se producen cambios y se alteran sensaciones, percepciones, conocimientos y emociones. Se modifica también la relación del sujeto que los experimenta respecto a sí mismo, a su identidad, a su cuerpo, al medio espacio-temporal y a los otros. En ellos se experimentan otras dimensiones de la realidad que no son asequibles a la conciencia ordinaria o que están deliberadamente bloqueadas. Pueden ser producidos voluntaria o involuntariamente. Estos EAC los tienen el $80 \%$ de las poblaciones que circundan el Mediterráneo y el $90 \%$ de las culturas mundiales". (Bernabé 2002).

${ }^{11}$ Cada vez es mayor el número de voces que se levantan entre los expertos y estudiosos de las posesiones canónicas de cristianismo reivindicando la oportunidad que la Antropología Social y Cultural ofrece para un mejor conocimiento del fenómeno y la aplicación de modelos relativistas más adecuados para el sentido social y cultural que en cada contexto presentan. Ver Tausiet 2002; Bernabé 2002; Moncó 2005; Miquel Pericás 2009

${ }^{12}$ Otro ejemplo significativo de posesas que expulsan maleficios corporales lo encontramos en Querétaro a finales del Siglo XVII [1691]. La epidemia de posesión únicamente afecta a un grupo de muchachas "españolas", como indica el expediente: Los maleficios expulsados por las jóvenes adolecen de una importante adecuación al dominio novohispano, al tiempo que reproducen los motivos peninsulares: "Francisca de Mexía vomita: huesos de aguacate y de mamey, y dos pedazos de elote todo revuelto", "tierra y piedrecitas como a manera de avellanas y otras mayores". Juana de los Reyes tampoco escatima su exhibición de vómitos extravagantes: expulsa vellones de lana, cabellos, agujas y alfileres, y solimán crudo. En este caso incluso la presencia demoníaca no sólo se asocia con el aparato digestivo, sino que además involucra a las partes sexuales: en algunas ocasiones la joven arrojó por sus genitales diversos artefactos, entre ellos un huso de fierros y un malacate de arriero. En otro ejemplo novohispano, del año 1717, la monja del convento de San Lorenzo llamada Paula Rosa, tosía y vomitaba alfileres, clavos, pedacitos de alambre y cabellos" (Bieñko de Peralta 2008).

${ }^{13}$ De hecho en la actualidad, los pueblos indígenas andinos no se caracterizan por el ejercicio de modelos chamánicos de posesión. Sí es frecuente la dislocación del especialista ritual, incorporando varias entidades auxiliares y sus voces sin perder la propia conciencia en sesiones en plena oscuridad, en el caso de los Andes del Sur entre los especialistas conocidos como ch'amakanis (aymara) o altomisayuq (quechua), así como la visión alucinógena, en el caso del Norte peruano por el consumo de productos como las mishas o el sanpedro (Trichocereus pachanoi) por parte de los curanderos y "maleros" del sector.

${ }^{14}$ Como han indicado Bernand y Gruzinski (1992), su sintomatología coincide con la enfermedad del "susto".

15 "Los cuerpos amerindios, contemplados como sucios y desarticulados, habían de ser objeto de una reconstrucción sistemática para que pudiesen alojar el alma, la sustancia más valiosa para la exportación de las culturas mediterráneas" (Gutiérrez 2010). ${ }^{16}$ En este sentido, paradójicamente la actividad evangelizadora con sus precauciones "demoníacas" propician el impacto del fenómeno entre aquellos a los que se deseaba "proteger" de sus malignas influencias. Obviamente no es ninguna novedad el considerar que el diablo católico extiende su presencia "peculiar" entre los grupos indígenas, precisamente al hilo del proceso evangelizador que le da carta de notoriedad. Así encontramos manifestaciones peculiares del maligno (no tan indeseable desde la perspectiva indígena contemporánea) entre los mineros quechuas potosinos, con su culto al "tío", el diablo, en el interior de los socavones mineros, pero igualmente convertido en ayudante chamánico con los especialistas rituales del Lago Titicaca (Fernández Juárez 2017).

${ }^{17}$ Machu. Entidad tutelar característica de los Andes que se relaciona con los antiguos, los seres que habitaban el mundo antes del diluvio universal.

${ }^{18}$ Modelo de transferencia que propicia el exorcismo, de tal forma que se espera que la entidad maléfica que genera el "susto" pase del cuerpo del enfermo al cuerpo del cuy.

${ }^{19}$ Se remarca en términos culinarios el carácter socializado del ser humano perteneciente al dominio de la cultura y por tanto pretendido de forma inadecuada por la entidad maléfica andina. Sólo en ciertas ocasiones ceremoniales, como en el festejo a los difuntos, las comidas humanas carecen de sal y ají en los Andes. La sal es empleada como referente cultural que humaniza y articula las viandas en las comidas.

${ }^{20}$ La idea expresada en el conjuro es la devolución del mal a quien lo originó

${ }^{21}$ En este caso la representación de los dolores que aquejan al enfermo y su vinculación con los nudos corporales de esa anatomía mágica que se pretende desanudar y deshacer en la recuperación de la víctima.

${ }^{22}$ Los textos clásicos de demonología europea insisten en salvaguardar el alma de los posesos del propio fenómeno de posesión. El diablo sólo puede apoderarse temporalmente de la carne corporal, bajo permiso divino, nunca del alma espiritual, circunstancia que aparece de forma inversa en los contextos de aflicción amerindios en los que son las entidades anímicas espirituales que configura la persona, el objeto de deseo y posesión maléfica. 
